Article

\title{
Thermoluminescence Characteristics of Terbium Doped Zinc Borates
}

\section{Nil Kucuk}

Physics Department, Faculty of Arts and Sciences, Bursa Uludag University, Gorukle Campus, 16059 Bursa, Turkey; nilkoc@uludag.edu.tr

Received: 19 September 2019; Accepted: 23 October 2019; Published: 25 October 2019

\begin{abstract}
In this work, structural and thermoluminescence (TL) characteristics for $\mathrm{ZnB}_{2} \mathrm{O}_{4}: \mathrm{xTb}^{3+}$ $(x=0.01,0.02,0.03,0.04,0.05$, and 0.10 mole) phosphors were investigated. The phosphors were prepared via synthesis of nitric acid. The $X$-ray diffraction (XRD) studies show that the synthesized samples can be indexed to nearly single-phase cubic $\mathrm{ZnB}_{2} \mathrm{O}_{4}$. The TL characteristics following ${ }^{90} \mathrm{Sr}$ beta irradiation $(40 \mathrm{mCi})$ were studied. TL intensity is found to depend on $\mathrm{Tb}$ concentration. The optimal concentration of the doped $\mathrm{Tb}^{3+}$ is $0.03 \mathrm{~mol}$ in TL measurements. TL dose responses of the phosphors to beta doses of $0.143,0.715,1.43,15,30$ and 60 Gy showed fairly linear behavior. The minimum detectable dose (MDD) value for $\mathrm{ZnB}_{2} \mathrm{O}_{4}: 0.04 \mathrm{~Tb}^{3+}$ was found to be $87 \mathrm{mGy}$. The kinetic parameters of the $\mathrm{ZnB}_{2} \mathrm{O}_{4}: 0.03 \mathrm{~Tb}^{3+}$ sample were estimated by the glow curve deconvolution, the initial rise, the curve fitting, and the peak shape methods. The results indicate that these phosphors are thought to be promising candidates as TL materials. The results provide valuable knowledge of the characteristics of $\mathrm{Tb}$-doped $\mathrm{ZnB}_{2} \mathrm{O}_{4}$ for use in dosimetry research.
\end{abstract}

Keywords: thermoluminescence; terbium; zinc borate; dosimetry

\section{Introduction}

Zinc borate $\left(\mathrm{ZnB}_{2} \mathrm{O}_{4}\right)$ is a boron-based inorganic material. In general, this material has low toxicity, wide-band-gap, excellent luminescence efficiency, good thermal stability, and low cost [1-4]. Over the past decade, zinc borates doped with different rare earth ions have been widely used by many research groups as host materials for luminescence applications. Examples include $\mathrm{ZnB}_{2} \mathrm{O}_{4}: \mathrm{Eu}^{3+}$ [4], $\mathrm{ZnB}_{2} \mathrm{O}_{4}: \mathrm{Ce}^{3+}, \mathrm{La}^{3+}$ [5], $\mathrm{ZnB}_{2} \mathrm{O}_{4}: \mathrm{Eu}^{3+}$ [6], $\mathrm{ZnB}_{2} \mathrm{O}_{4}: \mathrm{Tb}^{3+}$ [7], $\mathrm{ZnB}_{2} \mathrm{O}_{4}: \mathrm{Dy}^{3+}$ [8], $\mathrm{ZnB}_{2} \mathrm{O}_{4}: \mathrm{Bi}^{3+}, \mathrm{Eu}^{3+}$ [9], $\mathrm{ZnB}_{2} \mathrm{O}_{4}: \mathrm{Sm}^{3+}$ [10], $\mathrm{ZnB}_{2} \mathrm{O}_{4}: \mathrm{Pr}^{3+}$ [11], $\mathrm{ZnB}_{2} \mathrm{O}_{4}: \mathrm{Mn}^{2+}$ [12]. Various methods have been used to prepare the abovementioned luminescence materials. For instance, Zheng et al. produced a series of $\mathrm{Bi}^{3+}$ - and $\mathrm{Gd}^{3+}$-doped $\mathrm{ZnB}_{2} \mathrm{O}_{4}$ phosphors via the co-precipitation method [4]. Li et al. prepared $\mathrm{ZnB}_{2} \mathrm{O}_{4}: \mathrm{Tb}^{3+}$ phosphors at $950^{\circ} \mathrm{C}$ for $7 \mathrm{~h}$ via solid-state reactions [7]. The concentrations of doped $\mathrm{Tb}^{3+}$ ions in $\mathrm{ZnB}_{2} \mathrm{O}_{4}$ were taken as $1,2,4,8$ and $12 \mathrm{~mol} \%$. In this study, the photoluminescence (PL), thermoluminescence (TL) and dosimetric characteristics of $\mathrm{ZnB}_{2} \mathrm{O}_{4}: \mathrm{Tb}^{3+}$ phosphors exposed to a ${ }^{60} \mathrm{Co}$ gamma-source were investigated. It is stated that the TL glow peak of the $\mathrm{ZnB}_{2} \mathrm{O}_{4}: 0.04 \mathrm{~Tb}^{3+}$ sample is integrated in 408-513 K temperature range. TL-dose responses at 1-100 Gy gamma dose range for the samples were reported to be linear. In recent years, Rosario et al. prepared $\mathrm{ZnB}_{2} \mathrm{O}_{4}: \mathrm{Tb}^{3+}$ phosphors at $800{ }^{\circ} \mathrm{C}$ for $16 \mathrm{~h}$ via solvent evaporation [13]. The concentrations of doped $\mathrm{Tb}^{3+}$ ions in $\mathrm{ZnB}_{2} \mathrm{O}_{4}$ were taken as $0.5,1,2$, 4 and $8 \mathrm{~mol} \%$. In this study, $\mathrm{ZnB}_{2} \mathrm{O}_{4}: \mathrm{Tb}^{3+} \mathrm{TL}$ and radioluminescence (RL) properties were investigated following gamma irradiation and beta irradiation, respectively. It is stated that the glow curves of the samples consist of overlapping glow peaks. The TL intensity was reported to be dependent on both the impurity concentration and the heat treatment. Moreover, the samples were reported to have a linear dose-response between 0.022-27.7 Gy for beta and 0.5-50 Gy for gamma. 
To the best of our knowledge, the TL characteristics (i.e., glow curves, linear dose response and minimum detectable dose) for beta-irradiated $\mathrm{ZnB}_{2} \mathrm{O}_{4}: \mathrm{Tb}^{3+}$ phosphors have not been reported to date. In this study, $\mathrm{ZnB}_{2} \mathrm{O}_{4}: \mathrm{xTb}^{3+}(\mathrm{x}=0.01,0.02,0.03,0.04,0.05,0.10 \mathrm{~mol})$ phosphors were produced via synthesis of nitric acid. TL properties and MDD results of beta-irradiated $\mathrm{ZnB}_{2} \mathrm{O}_{4}: \mathrm{Tb}^{3+}$ phosphors were reported. Furthermore, the kinetic parameters of $\mathrm{ZnB}_{2} \mathrm{O}_{4}: 0.03 \mathrm{~Tb}^{3+}$ were estimated by the glow curve deconvolution, the initial rise, the curve fitting, and the peak shape methods.

\section{Materials and Methods}

$\mathrm{ZnB}_{2} \mathrm{O}_{4}: \mathrm{xTb}^{3+}(\mathrm{x}=0.01,0.02,0.03,0.04,0.05,0.10 \mathrm{~mol})$ phosphors were synthesized with a nitric-acid method as follows [14-16]: Suitable quantities of $\mathrm{ZnO}$ (99.99\%) (Thermo Fisher Scientific, Kandel, Germany), $\mathrm{H}_{3} \mathrm{BO}_{3}$ (99.99\%) (Thermo Fisher Scientific, Kandel, Germany) and $\mathrm{Tb}_{4} \mathrm{O}_{7}(99.9 \%)$ (Thermo Fisher Scientific, Kandel, Germany) powder materials were placed in a glass beaker. The solution of $1 \mathrm{M} \mathrm{HNO}_{3}$ (nitric acid) (Thermo Fisher Scientific, Kandel, Germany) used as catalyst was poured into the mixture. The combination was mixed for about 4 hours using a magnetic stirrer (Cleaver Scientific Ltd, Warwickshire, United Kingdom) working at a temperature of about $80{ }^{\circ} \mathrm{C}$. Upon completion of stirring, a dry matter was obtained. The agate mortar was then used to grind the dry matter. The matter was ground until it achieved a fine powder form and was calcined in an alumina crucible in a tube oven (Protherm, Ankara, Turkey), at $450{ }^{\circ} \mathrm{C}$ for 5 hours to remove possible organic compounds. The calcined matter was once again milled in an agate mortar. The powder matter obtained was pressed and placed in porcelain combustion tanks and annealed in a tube oven at $900{ }^{\circ} \mathrm{C}$ for 2 hours and naturally cooled to room temperature. The annealed matter was once again milled in an agate mortar and transferred in Eppendorf tubes.

XRD patterns of the phosphors prepared at various $\mathrm{Tb}$ concentration were performed using a Rigaku Ultima IV X-ray diffractometer (Rigaku, Toronto, Canada) using Cu- $\mathrm{K}_{\alpha}(\lambda=1.5405 \AA$ ) radiation.

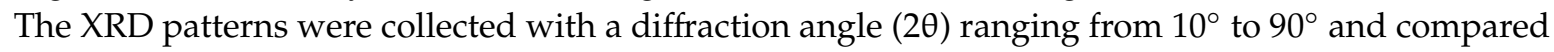
with the XRD ICDD file of the International Centre for Diffraction Data using X-powder diffraction software (PDF Card No. 39-1126). The Rietveld refinement method with the FullProf Software was used to purify the XRD patterns obtained. A LEO $1430 \mathrm{VP}$ scanning electron microscope (SEM) (Zeiss, Düsseldorf, Germany) was used to examine the microstructure. In addition, energy-dispersive X-ray (EDX) spectroscopy (Zeiss, Düsseldorf, Germany) was used to examine the elemental composition of the samples.

TL measurements were carried out on $10 \mathrm{mg}$ samples using an automated Risø TL/OSL DA-20 reader (DTU Nutech, Roskilde, Denmark) with Corning 7/59 and Schott BG/39 optical filters in a nitrogen atmosphere. The TL measurement system has an internal ${ }^{90} \mathrm{Sr} /{ }^{90} \mathrm{Y} \beta$-source with a dose rate of $0.143 \mathrm{~Gy} . \mathrm{s}^{-1}$. During measurements of all the samples, readings were taken up to $450{ }^{\circ} \mathrm{C} / \mathrm{s}$ for the heating rate of $5{ }^{\circ} \mathrm{C} / \mathrm{s}$. TL peak intensities from the areas under dosimetric peaks were determined. The background corrections were made in TL glow curves for each sample.

\section{Results and Discussion}

Obtained powder samples were subject to X-ray powder diffraction (XRD) in order to check their phase purity. Furthermore, the standard XRD pattern of $\mathrm{ZnB}_{2} \mathrm{O}_{4}$ (PDF Card No. 39-1126) was selected for comparison. Powder XRD patterns of $\mathrm{ZnB}_{2} \mathrm{O}_{4}$ doped with various concentrations of $\mathrm{Tb}^{3+}$ ions are illustrated in Figure 1a. Powder XRD patterns showed intense and sharp peaks at almost the same angle position. This is a strong indication that the samples have high crystallinity. These diffraction patterns are in good agreement with the standard JCPDS card No. 39-1126, which represents the pure phase of $\mathrm{ZnB}_{2} \mathrm{O}_{4}$. No additional signal was observed in the XRD patterns of other phosphors, except for the $\mathrm{ZnB}_{2} \mathrm{O}_{4}: 0.10 \mathrm{~Tb}^{3+}$ phosphor. The decrease in crystallization of Tb-doped $\mathrm{ZnB}_{2} \mathrm{O}_{4}$ with increased quantities of Tb-dopant was seen in the XRD patterns of $\mathrm{ZnB}_{2} \mathrm{O}_{4}: 0.10 \mathrm{~Tb}^{3+}$ phosphor. This can be attributed to the change in dopant loads leading to defect formation in the cage. In general, it can be concluded from these data that the structure of the samples does not change after doping with $\mathrm{Tb}^{3+}$. 
The effective ionic radii of dopant and host ions are given as follows: $\mathrm{Zn}^{2+}=0.60 \AA$ (Coordination IV), $\mathrm{B}^{3+}=0.21 \AA$ (Coordination IV), $\mathrm{Tb}^{3+}=0.92 \AA$ (Coordination VI) [17]. $\mathrm{Tb}^{3+}$ doping ions cannot replace the $\mathrm{B}^{3+}$ ions site in the $\mathrm{ZnB}_{2} \mathrm{O}_{4}$ host lattice due to their different ionic radii. This can be linked to the smaller ionic radius of $\mathrm{B}^{3+}$ compared to that of $\mathrm{Zn}^{2+}$. For this reason, it is more likely for $\mathrm{Tb}^{3+}$ ions to replace $\mathrm{Zn}^{2+}$ ions in the host lattice. The concentration of the impurity phases is so small that even though the concentration of $\mathrm{Tb}^{3+}$ doping is as high as $10 \mathrm{~mol} \%, \mathrm{~Tb}^{3+}$ has no effect on the crystal structure of $\mathrm{ZnB}_{2} \mathrm{O}_{4}$. It should be remembered that replacing $\mathrm{Zn}^{2+}$ ions with $\mathrm{Tb}^{3+}$ causes not only a charge imbalance but also a volume imbalance. This leads to crystal lattice expansion because the $\mathrm{Tb}^{3+}$ radius is greater than that of the altered $\mathrm{Zn}^{2+}$. However, the recorded XRD results are consistent with the literature reports $[1,10,11]$.

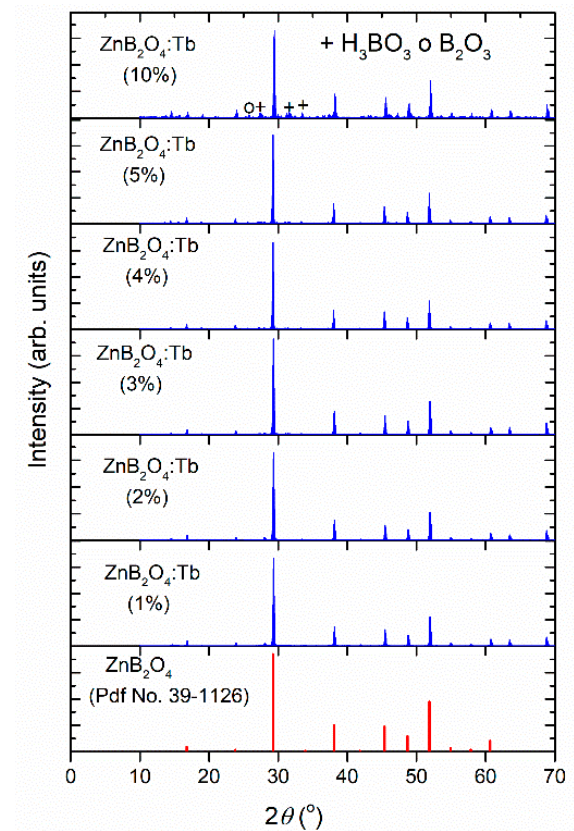

(a)

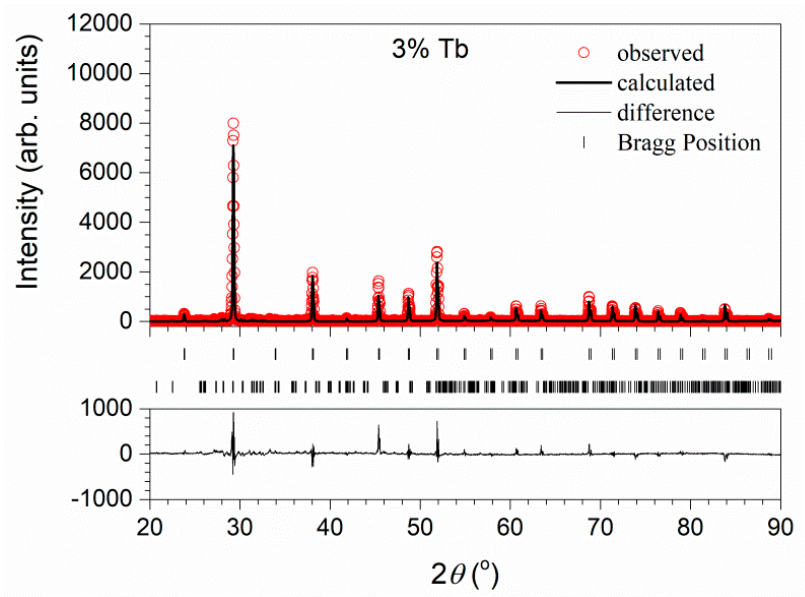

(b)

Figure 1. (a) XRD patterns for $\mathrm{ZnB}_{2} \mathrm{O}_{4}: \mathrm{Tb}^{3+}$ phosphors. The standard XRD pattern of $\mathrm{ZnB}_{2} \mathrm{O}_{4}$ is taken from JCPDS Card No. 39-1126. (b) The refined XRD pattern of $\mathrm{ZnB}_{2} \mathrm{O}_{4}: 0.03 \mathrm{~Tb}^{3+}$ sample.

After refining XRD patterns using FullProf software, lattice parameters were calculated. The refined XRD of $\mathrm{ZnB}_{2} \mathrm{O}_{4}: 0.03 \mathrm{~Tb}^{3+}$ sample is seen in Figure $1 \mathrm{~b}$. In this figure, the observed pattern, the calculated pattern and the difference between the observed-calculated patterns are represented by red circles, a thick black line and a thin black line, respectively. $\mathrm{ZnB}_{2} \mathrm{O}_{4}: \mathrm{Tb}^{3+}$ samples exhibit a cubic structure with the space group $I-43 \mathrm{~m}$. It can be said that the crystal structure remains the same with the addition of $\mathrm{Tb}$ and that the lattice parameters undergo small changes. The maximum increase in lattice parameter "a" is $0.028 \%$ for $3 \% \mathrm{~Tb}$. When the amount of $\mathrm{Tb}$ doping increases by $3 \%$, the lattice parameter "a" and the unit cell volume slowly increase as the atomic radius of $\mathrm{Tb}$ is greater than that of $\mathrm{Zn}$. When the doping amount is above 3\%, the lattice parameter "a" and unit cell volume are reduced due to lattice distortion or migration of the doping ions to the interstitial positions [18]. In addition, the diffraction pattern of the $\mathrm{ZnB}_{2} \mathrm{O}_{4}: 0.10 \mathrm{~Tb}^{3+}$ sample indicates the presence of small impurity phases, which are $\mathrm{H}_{3} \mathrm{BO}_{3}$ and $\mathrm{B}_{2} \mathrm{O}_{3}$. The parameters obtained for $\mathrm{ZnB}_{2} \mathrm{O}_{4}: \mathrm{Tb}^{3+}$ samples are given in Table 1 .

Figure 2 shows an SEM image of the $\mathrm{ZnB}_{2} \mathrm{O}_{4}: 0.03 \mathrm{~Tb}^{3+}$ sample. It is observed that the particles in the zinc borate are slightly agglomerated and thus result in an inhomogeneous structure. SEM-EDX analysis was performed to determine the chemical composition of the sample in an area of $10 \times 10 \mu \mathrm{m}^{2}$. Table 2 shows the atomic ratios of $\mathrm{Zn} / \mathrm{O}, \mathrm{Tb} / \mathrm{Zn}$ and $\mathrm{Tb} / \mathrm{O}$. The results show that the nominal ratios of zinc borate are consistent with the EDX results. 
Table 1. The parameters calculated from the XRD patterns of $\mathrm{ZnB}_{2} \mathrm{O}_{4}: \mathrm{Tb}^{3+}$ samples.

\begin{tabular}{cccc}
\hline Phase Content & $\begin{array}{c}\text { Cubic }(\mathbf{I}-43 m) \\
\text { Lattice Para. }(\AA)\end{array}$ & $\mathbf{V}\left(\AA^{3}\right)$ & $\chi^{\mathbf{2}}$ \\
\hline $1 \% \mathrm{~Tb}$ & $\mathrm{~A}=7.4722$ & 417.196 & 0.70 \\
$2 \% \mathrm{~Tb}$ & $\mathrm{~A}=7.4737$ & 417.452 & 5.39 \\
$3 \% \mathrm{~Tb}$ & $\mathrm{~A}=7.4743$ & 417.554 & 4.70 \\
$4 \% \mathrm{~Tb}$ & $\mathrm{~A}=7.4725$ & 417.253 & 3.20 \\
$5 \% \mathrm{~Tb}$ & $\mathrm{~A}=7.4722$ & 417.203 & 5.20 \\
$10 \% \mathrm{~Tb}$ & $\mathrm{~A}=7.4723$ & 417.218 & 5.18 \\
\hline
\end{tabular}

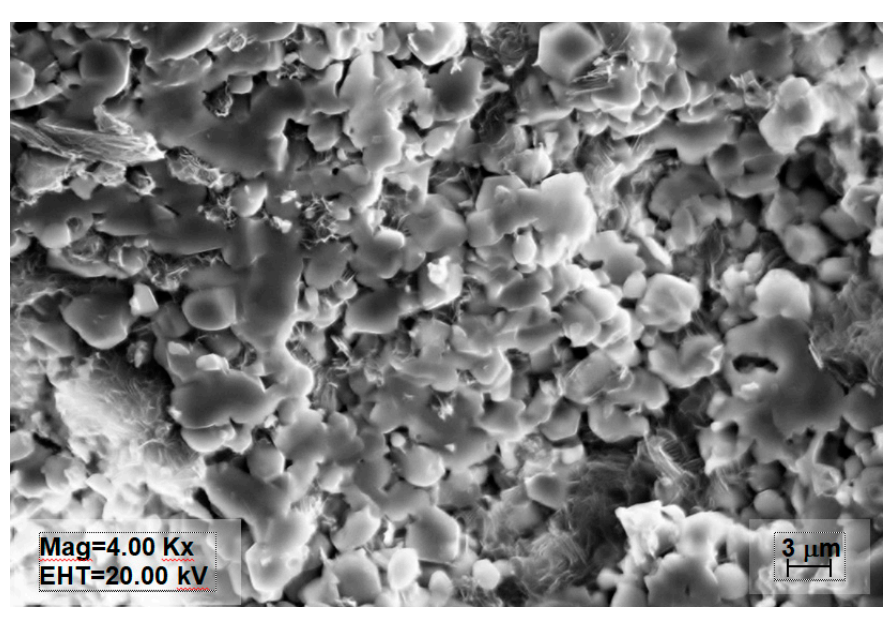

Figure 2. SEM micrographs of $\mathrm{ZnB}_{2} \mathrm{O}_{4}: 0.03 \mathrm{~Tb}^{3+}$.

Table 2. The atomic ratios of the $\mathrm{ZnB}_{2} \mathrm{O}_{4}: 0.03 \mathrm{~Tb}^{3+}$ obtained from the EDX results.

\begin{tabular}{cccc}
\hline & $\begin{array}{c}\text { Zn/O } \\
\text { Atomic Ratio }\end{array}$ & $\begin{array}{c}\text { Tb/Zn } \\
\text { Atomic Ratio }\end{array}$ & $\begin{array}{c}\text { Tb/O } \\
\text { Atomic Ratio }\end{array}$ \\
\hline Nominal & 0.2425 & 0.0309 & 0.0075 \\
$3 \% \mathrm{~Tb}$ & 0.2317 & 0.0332 & 0.0067 \\
\hline
\end{tabular}

Figure 3 shows the TL glow curves for the selected $\mathrm{ZnB}_{2} \mathrm{O}_{4}: \mathrm{xTb}^{3+}(\mathrm{x}=0.01,0.03$, and $0.05 \mathrm{~mol})$ phosphors. As seen from Figure 3, the TL glow curves showed a dosimetric peak at about $200{ }^{\circ} \mathrm{C}$ for $\mathrm{ZnB}_{2} \mathrm{O}_{4}: 0.01 \mathrm{~Tb}^{3+}$ and about $210{ }^{\circ} \mathrm{C}$ for $\mathrm{ZnB}_{2} \mathrm{O}_{4}: 0.03 \mathrm{~Tb}^{3+}$ and $\mathrm{ZnB}_{2} \mathrm{O}_{4}: 0.05 \mathrm{~Tb}^{3+}$. In addition, as the beta dose irradiation increases, a low-severity shoulder is seen in the temperature range of $260-300{ }^{\circ} \mathrm{C}$. No significant shifts were observed in the maximum peak temperature of the main glow peak with increasing beta dose irradiation for all the phosphors produced. Additionally, the increase in the beta dose irradiation caused an increase in the intensity of the TL. It is known that the dependence of the TL responses on the beta dose irradiation provides important information about the trapping of trapped electrons and holes. Thus, it can be assumed that more charge carriers are trapped as the beta dose irradiation increases. Subsequent heating releases some of the trapped electrons with an associated emission of light in the form of glow curves [19]. This result shows that there are strong interactions between internal defects and dopant. For the $30 \mathrm{~Gy}$ beta dose, the glow peak intensities of $\mathrm{ZnB}_{2} \mathrm{O}_{4}: 0.01 \mathrm{~Tb}^{3+}, \mathrm{ZnB}_{2} \mathrm{O}_{4}: 0.03 \mathrm{~Tb}^{3+}$ and $\mathrm{ZnB}_{2} \mathrm{O}_{4}: 0.05 \mathrm{~Tb}^{3+}$ phosphors increased by about 19,46 and 21 times compared to the $1.43 \mathrm{~Gy}$ beta dose. 


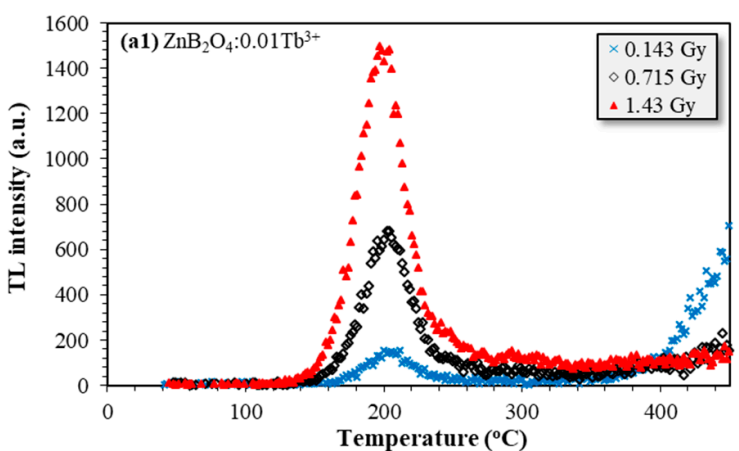

(a1)

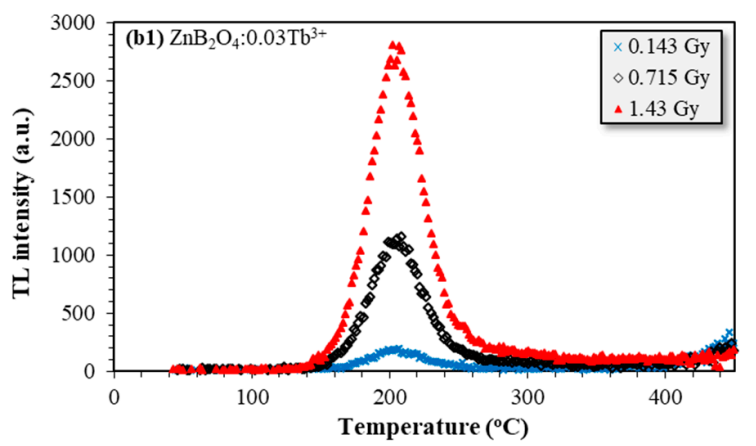

(b1)

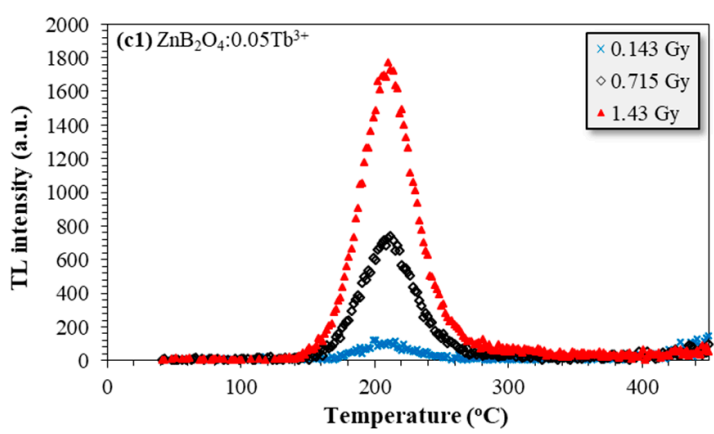

(c1)

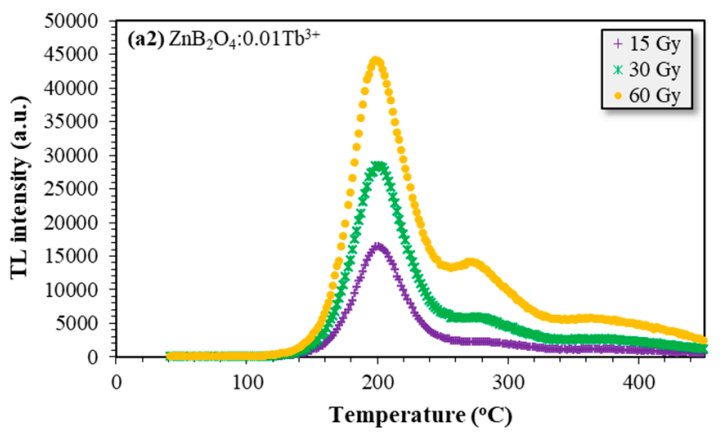

(a2)

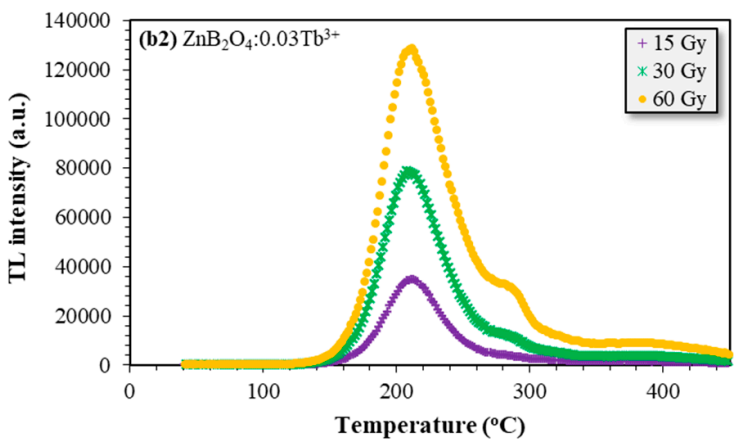

(b2)

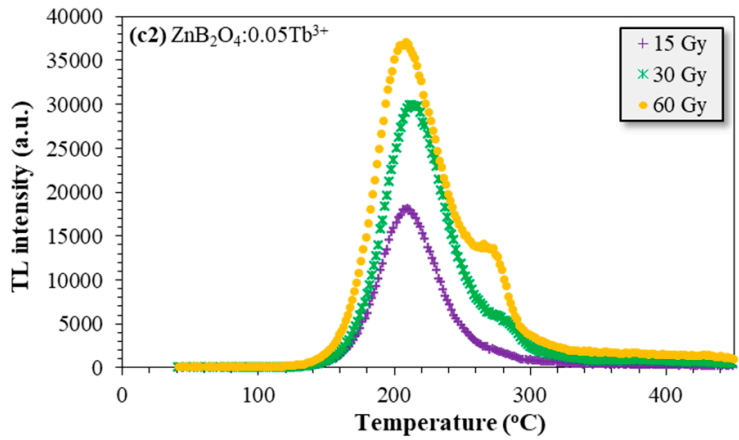

(c2)

Figure 3. Experimental TL glow curves of $\mathrm{ZnB}_{2} \mathrm{O}_{4}: \mathrm{xTb}^{3+}(\mathbf{a} 1-\mathbf{a} 2) \mathrm{x}=0.01,(\mathbf{b} 1-\mathbf{b} 2) \mathrm{x}=0.03$ and $(\mathbf{c 1 - c 2})$ $\mathrm{x}=0.05$.

Figure 4 shows the TL glow curves of all the phosphors exposed to the 30 Gy beta dose. According to this figure, it has been observed that all the phosphors have different TL intensities and there are very few differences in the peak structures. The low-intensity shoulder observed at $260-290{ }^{\circ} \mathrm{C}$ can be said to vary with beta dose irradiation. It is clear that the main TL peak intensity of $\mathrm{ZnB}_{2} \mathrm{O}_{4}: 0.03 \mathrm{~Tb}^{3+}$ phosphor is much more severe than that of the other phosphors. It is also found that max peak intensity and max peak temperatures of the glow curve are dependent on the amount of $\mathrm{Tb}$ concentration. Due to the $\mathrm{Tb}$-concentration quenching effect, the TL intensity initially increases with increasing $\mathrm{Tb}$ concentration, and then reaches the maximum value at the optimum concentration level [5]. The $\mathrm{Tb}^{3+}$ ions surrounded by the host lattice form the luminescence centers in the sample. At a high $\mathrm{Tb}^{3+}$ concentration, stability of luminescence centers and lattice structure can be disrupting and this will lead to an increased interaction between the periodicity of the lattice and luminescence center. This will cause a decrease of the luminescence intensity [20]. Furthermore, the peak temperature of the main glow peak appears to shift slightly as the Tb-concentration level increases. Thus, it can be deduced that the distributions of the traps produced by beta dose irradiation can be changed by changing the concentrations of $\mathrm{Tb}^{3+}$ ion added to zinc borate. 


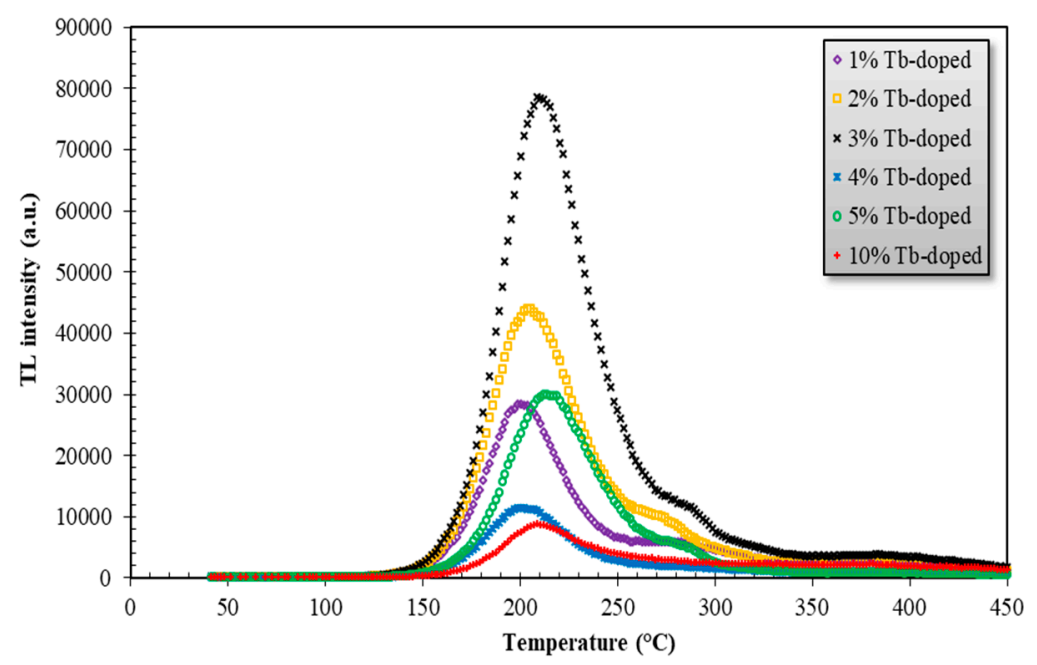

Figure 4. TL glow curves of $\mathrm{ZnB}_{2} \mathrm{O}_{4}: \mathrm{Tb}^{3+}$ phosphors for a 30 Gy beta dose.

Figure 5 shows TL dose-response curves of the selected $\mathrm{ZnB}_{2} \mathrm{O}_{4}: 0.02 \mathrm{~Tb}^{3+}$ and $\mathrm{ZnB}_{2} \mathrm{O}_{4}: 0.05 \mathrm{~Tb}^{3+}$ phosphors. $\mathrm{TL}=a(\mathrm{D})^{k}$ is the best fit equation for the line passing through the data points [14,21]. TL dose-response curves were found to be linear in the 0.143-60 Gy beta dose range. The $k$ values of phosphors are in the range of 0.864 to 1.050. MDD values for $\mathrm{ZnB}_{2} \mathrm{O}_{4}: \mathrm{Tb}^{3+}$ phosphors were determined as three-times the background count [22,23]. The best MDD value for $\mathrm{ZnB}_{2} \mathrm{O}_{4}: 0.04 \mathrm{~Tb}^{3+}$ was found to be $0.087 \mathrm{~Gy}$. MDD values for $\mathrm{ZnB}_{2} \mathrm{O}_{4}: 0.01 \mathrm{~Tb}^{3+}, \mathrm{ZnB}_{2} \mathrm{O}_{4}: 0.02 \mathrm{~Tb}^{3+}, \mathrm{ZnB}_{2} \mathrm{O}_{4}: 0.03 \mathrm{~Tb}^{3+}, \mathrm{ZnB}_{2} \mathrm{O}_{4}: 0.05 \mathrm{~Tb}^{3+}$ and $\mathrm{ZnB}_{2} \mathrm{O}_{4}: 0.10 \mathrm{~Tb}^{3+}$ were reported as $0.189,0.135,0.101,0.140$ and $0.105 \mathrm{~Gy}$, respectively. For $\mathrm{ZnB}_{2} \mathrm{O}_{4}: \mathrm{Tb}^{3+}$ phosphors, maximum peak temperature $\left(T_{\mathrm{m}}\right)$, background counts, values of $k$ with standard error $(\Delta k)$ and MDD values are given in Table 3.

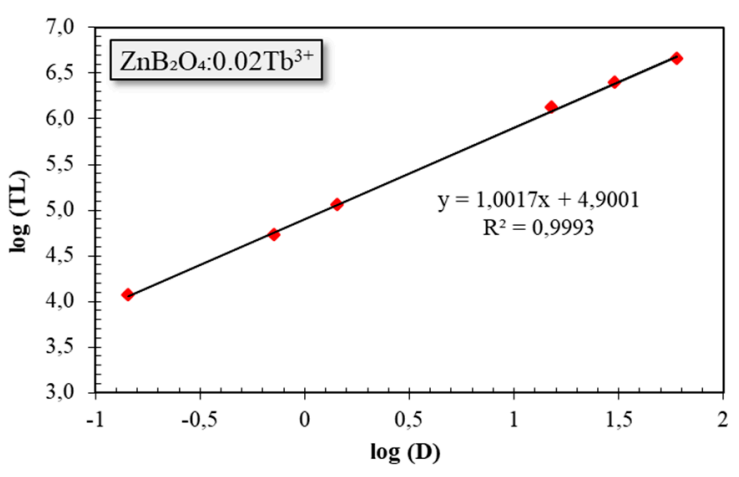

(a)

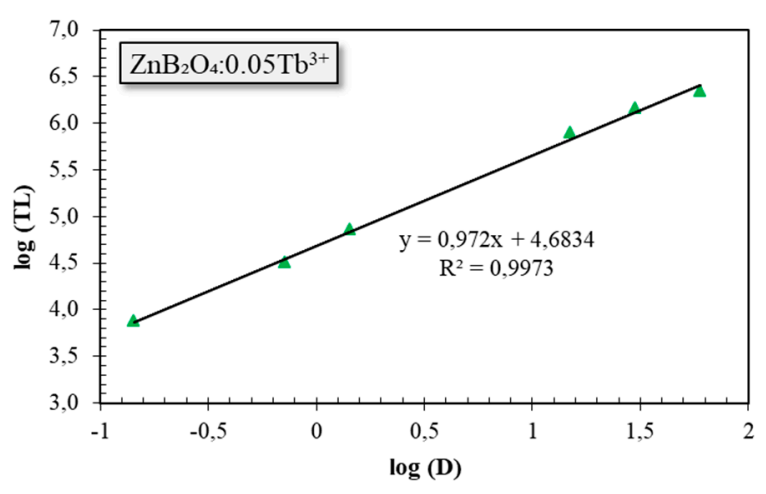

(b)

Figure 5. TL dose-response curves of $(\mathbf{a}) \mathrm{ZnB}_{2} \mathrm{O}_{4}: 0.02 \mathrm{~Tb}^{3+}$, (b) $\mathrm{ZnB}_{2} \mathrm{O}_{4}: 0.05 \mathrm{~Tb}^{3+}$ for $0.143-60 \mathrm{~Gy}$ beta dose range. The linear fit dose response is indicated by a solid line.

Table 3. Dose responses and MDD values of $\mathrm{ZnB}_{2} \mathrm{O}_{4}: \mathrm{Tb}^{3+}$ samples.

\begin{tabular}{ccccc}
\hline Sample & $\boldsymbol{T}_{\mathbf{m}}\left({ }^{\circ} \mathbf{C}\right)$ & Background Counts & $\boldsymbol{k} \pm \boldsymbol{\Delta} \boldsymbol{k}$ & MDD (Gy) \\
\hline $\mathrm{ZnB}_{2} \mathrm{O}_{4}: 0.01 \mathrm{~Tb}^{3+}$ & 200 & 2500 & $0.960 \pm 0.086$ & $0.189 \pm 0.038$ \\
$\mathrm{ZnB}_{2} \mathrm{O}_{4}: 0.02 \mathrm{~Tb}^{3+}$ & 205 & 2729 & $1.002 \pm 0.013$ & $0.135 \pm 0.006$ \\
$\mathrm{ZnB}_{2} \mathrm{O}_{4}: 0.03 \mathrm{~Tb}^{3+}$ & 210 & 3524 & $1.050 \pm 0.042$ & $0.101 \pm 0.010$ \\
$\mathrm{ZnB}_{2} \mathrm{O}_{4}: 0.04 \mathrm{~Tb}^{3+}$ & 205 & 477 & $0.883 \pm 0.066$ & $0.087 \pm 0.056$ \\
$\mathrm{ZnB}_{2} \mathrm{O}_{4}: 0.05 \mathrm{~Tb}^{3+}$ & 210 & 1392 & $0.972 \pm 0.025$ & $0.140 \pm 0.031$ \\
$\mathrm{ZnB}_{2} \mathrm{O}_{4}: 0.10 \mathrm{~Tb}^{3+}$ & 210 & 691 & $0.864 \pm 0.096$ & $0.105 \pm 0.010$ \\
\hline
\end{tabular}


Kinetic parameters provide important information regarding the TL mechanism of the material. Well-known kinetic parameters increase the reliability of dosimetric studies. Therefore, the kinetic parameters of $\mathrm{ZnB}_{2} \mathrm{O}_{4}: 0.03 \mathrm{~Tb}^{3+}$ were determined using the glow curve deconvolution, the initial rise, the curve fitting, and the peak shape methods. The glow curve deconvolution method has great advantages over experimental methods [24]. It can be used to simultaneously determine the kinetic parameters of TL peaks without additional thermal treatments and experimental repetitions. In addition, this method uses all the data points in the glow curve during curve fitting procedures [19]. Maximum peak temperature for a constant heating rate should not be influenced by other experimental parameters. It was noted that the peak maximum positions did not change with dose increase for first-order kinetics. However, the peak shifts to the lower-temperature zone as the dose increases for general-order kinetics $(1<b<2)$. As shown in Figure 3, the peak temperature of the luminance peak at about $200{ }^{\circ} \mathrm{C}$ does not shift with dose increase, and this point indicates that this peak has first-order kinetics [21-23]. In this study, decomposition was made with GlowFit software on the TL glow curve of the $\mathrm{ZnB}_{2} \mathrm{O}_{4}: 0.03 \mathrm{~Tb}^{3+}$ sample selected for a $30 \mathrm{~Gy}$ beta dose. Figure 6a shows the analyzed glow curve of the $\mathrm{ZnB}_{2} \mathrm{O}_{4}: 0.03 \mathrm{~Tb}^{3+}$ sample. As can be seen, this TL glow curve consists of five separated peaks. The TL glow curves of the $\mathrm{ZnB}_{2} \mathrm{O}_{4}: 0.03 \mathrm{~Tb}^{3+}$ sample exhibit one prominent glow peak at around $215^{\circ} \mathrm{C}$ (peak 2), two-less dominant glow peaks at around $201{ }^{\circ} \mathrm{C}$ (peak 1) and around $235^{\circ} \mathrm{C}$ (peak 3), one low-intensity peak at around $265^{\circ} \mathrm{C}$, and one shoulder peak at around $358^{\circ} \mathrm{C}$ (peak 5). The accuracy of these values is supported by the FOM (figure of merit) value. A parameter set is acceptable if the FOM is less than $5 \%$ [12]. The FOM value of the $\mathrm{ZnB}_{2} \mathrm{O}_{4}: 0.03 \mathrm{~Tb}^{3+}$ sample was found to be $2.32 \%$.

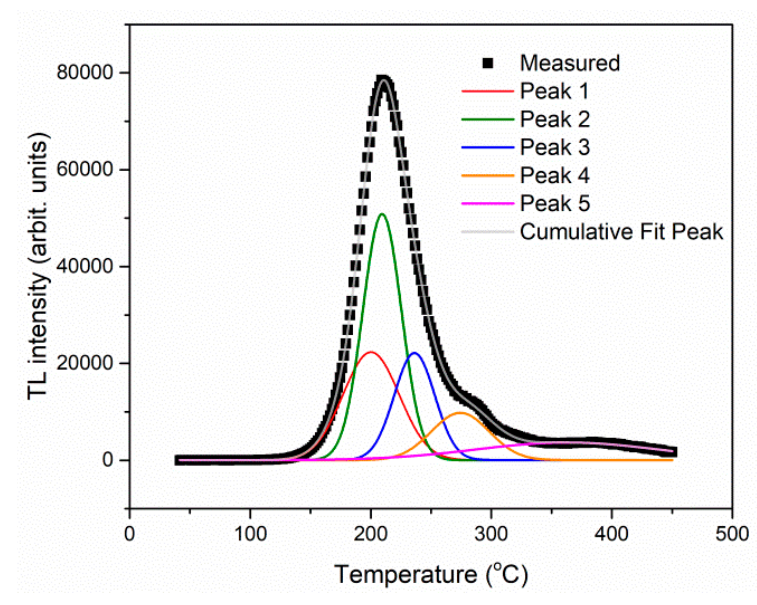

(a)

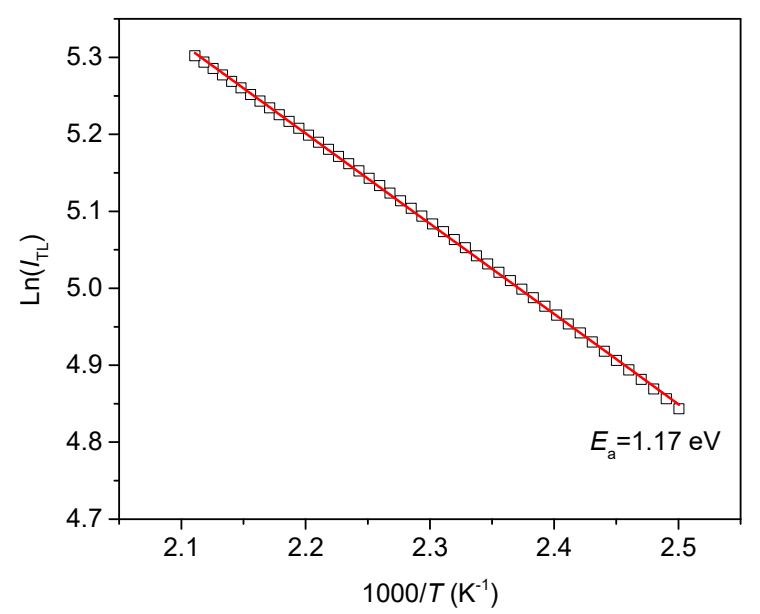

(b)

Figure 6. (a) CGCD of the TL glow curve of the $\mathrm{ZnB}_{2} \mathrm{O}_{4}: 0.03 \mathrm{~Tb}^{3+}$ sample for a $30 \mathrm{~Gy}$. (b) TL intensity versus 1000/T. Open shapes and lines present the experimental data and theoretical fit, respectively.

The kinetic parameters obtained by the glow curve deconvolution method are given in Table 4, together with $T_{\mathrm{m}}$ values. $E_{\mathrm{a}}$ is the activation energy and $s$ is the frequency factor. The activation energies and the frequency factors of the $\mathrm{ZnB}_{2} \mathrm{O}_{4}: 0.03 \mathrm{~Tb}^{3+}$ sample were determined as $1.49 \mathrm{eV}$ and $2.79 \times 10^{15} \mathrm{~s}^{-1}$ for the first peak, $1.27 \mathrm{eV}$ and $3.88 \times 10^{12} \mathrm{~s}^{-1}$ for the second peak, $1.20 \mathrm{eV}$ and $2.20 \times 10^{11} \mathrm{~s}^{-1}$ for the third peak, $0.71 \mathrm{eV}$ and $6.20 \times 10^{5} \mathrm{~s}^{-1}$ for the fourth peak, and $0.50 \mathrm{eV}$ and $7.24 \times 10^{2} \mathrm{~s}^{-1}$ for the fifth peak, respectively.

The initial rise method-a powerful technique independent from the order of kinetics in the TL processes-was also used to calculate the activation energy. The TL intensity in the initial portion ( $10 \%$ of its maximum intensity) of the glow curve is proportional to $\exp \left(-E_{\mathrm{a}} / \mathrm{kT}\right)$ [25]. This relation gives an opportunity to evaluate the $E_{\mathrm{a}}$ value from the slope of the $\ln \left(I_{\mathrm{TL}}\right)$ vs. $1 / T$ graph. Figure $6 \mathrm{~b}$ presents the corresponding plots (open shapes) and their linear fits (solid lines). The values of $E_{\mathrm{a}}$ obtained by this method for the $\mathrm{ZnB}_{2} \mathrm{O}_{4}: 0.03 \mathrm{~Tb}^{3+}$ sample are as obtained $1.17 \mathrm{eV}$ (Table 4). 
The curve fitting method is based on the fitting of the observed glow curve to the theoretical expressions. The details of this method were reported in reference [26]. The fitting process has been carried using the equations given in Reference [26] for different values of the parameter, $b$. The best fitting was achieved for $b=1.1$, which states the presence of first order kinetics. The activation energy obtained from the fitted curve was $1.20 \mathrm{eV}$ and is given in Table 4 .

The peak shape method is generally called Chen's method, which is used to determine the kinetic parameters of the main glow peak of the TL materials [27]. This method is mainly based on the temperatures $T_{\mathrm{m}}, T_{1}$ and $T_{2}$, which are the peak temperatures, the temperatures at half of the maximum intensity, on the ascending and descending parts of the peak, respectively. Geometrical shape parameters (i.e., $T_{\mathrm{m}}, T_{1}, T_{2}, \tau, \delta$ and $\omega$ ) were initially determined with the help of the TL glow curves. Where $\omega=T_{2}-T_{1}$ is the total peak width at half of the maximum intensity, $\tau=T_{\mathrm{m}}-T_{1}$ is the lower-temperature half-width, $\delta=T_{2}-T_{\mathrm{m}}$ is the upper-temperature half-width, and $\mu_{\mathrm{g}}=\delta / \omega$ is the symmetry factor. Then, the peak shape method was applied to $\mathrm{ZnB}_{2} \mathrm{O}_{4}: 0.03 \mathrm{~Tb}^{3+}$ phosphor for $30 \mathrm{~Gy}$. The mean values of $E_{\mathrm{a}}$ and $s$ obtained by this method for the $\mathrm{ZnB}_{2} \mathrm{O}_{4}: 0.03 \mathrm{~Tb}^{3+}$ sample were determined as $1.25 \mathrm{eV}$ and $8.32 \times 10^{15} \mathrm{~s}^{-1}$ for the first peak, $1.29 \mathrm{eV}$ and $1.33 \times 10^{12} \mathrm{~s}^{-1}$ for the second peak, $1.21 \mathrm{eV}$ and $2.19 \times 10^{11} \mathrm{~s}^{-1}$ for the third peak, $0.73 \mathrm{eV}$ and $2.13 \times 10^{5} \mathrm{~s}^{-1}$ for the fourth peak, and $0.51 \mathrm{eV}$ and $1.02 \times 10^{2} \mathrm{~s}^{-1}$ for the fifth peak, respectively (Table 4). As seen from Table 4 , there is a good agreement between all the results.

Table 4. The kinetic parameters obtained by different methods of $\mathrm{ZnB}_{2} \mathrm{O}_{4}: 0.03 \mathrm{~Tb}^{3+}$ for a $30 \mathrm{~Gy}$.

\begin{tabular}{|c|c|c|c|c|c|c|c|c|}
\hline \multirow[t]{2}{*}{ Peak } & \multirow[t]{2}{*}{$T_{\mathrm{m}}\left({ }^{\circ} \mathrm{C}\right)$} & \multicolumn{2}{|c|}{$\begin{array}{l}\text { Glow Curve } \\
\text { Deconvolution }\end{array}$} & \multirow{2}{*}{$\begin{array}{c}\begin{array}{c}\text { Initial } \\
\text { Rise }\end{array} \\
E_{\mathrm{a}}(\mathrm{eV})\end{array}$} & \multirow{2}{*}{$\begin{array}{c}\text { Curve } \\
\text { Fitting } \\
E_{\mathrm{a}}(\mathrm{eV})\end{array}$} & \multicolumn{3}{|c|}{ Peak Shape } \\
\hline & & $E_{\mathrm{a}}(\mathrm{eV})$ & $s\left(\mathrm{~s}^{-1}\right)$ & & & $E_{\mathrm{a}}(\mathrm{eV})$ & $\mu_{g}$ & $s\left(\mathrm{~s}^{-1}\right)$ \\
\hline & & & & 1.17 & 1.20 & & & \\
\hline 1 & 201 & 1.49 & $2.79 \times 10^{15}$ & & & 1.25 & 0.50 & $8.32 \times 10^{15}$ \\
\hline 2 & 215 & 1.27 & $3.88 \times 10^{12}$ & & & 1.29 & 0.51 & $1.33 \times 10^{12}$ \\
\hline 3 & 235 & 1.20 & $2.20 \times 10^{11}$ & & & 1.21 & 0.51 & $2.19 \times 10^{11}$ \\
\hline 4 & 265 & 0.71 & $6.20 \times 10^{5}$ & & & 0.73 & 0.50 & $2.13 \times 10^{5}$ \\
\hline \multirow[t]{2}{*}{5} & 358 & 0.50 & $7.24 \times 10^{2}$ & & & 0.51 & 0.49 & $1.02 \times 10^{2}$ \\
\hline & & Mean:1.03 & & & & Mean:1.00 & & \\
\hline
\end{tabular}

\section{Conclusions}

$\mathrm{ZnB}_{2} \mathrm{O}_{4}: \mathrm{Tb}^{3+}$ phosphors were successfully prepared using a nitric acid synthesis method. The results of the $\mathrm{XRD}$ analysis showed that the synthesized phosphors could be indexed to a pure, cubic phase of $\mathrm{ZnB}_{2} \mathrm{O}_{4}$. The TL properties and dependence on the dose of beta irradiation of the phosphors have been investigated by the TL technique. The TL peaks of the samples are present at around $200-210{ }^{\circ} \mathrm{C}$. It has been found that the TL intensity of the $\mathrm{ZnB}_{2} \mathrm{O}_{4}: 0.03 \mathrm{~Tb}^{3+}$ sample is much stronger than that of the other samples. The dose responses to beta irradiation of all the powder samples showed good linearity in the dose range between 0.143-60 Gy. The MDD value for $\mathrm{ZnB}_{2} \mathrm{O}_{4}: 0.04 \mathrm{~Tb}^{3+}$ sample was found to be 87 mGy. MDD values for $\mathrm{ZnB}_{2} \mathrm{O}_{4}: 0.01 \mathrm{~Tb}^{3+}, \mathrm{ZnB}_{2} \mathrm{O}_{4}: 0.02 \mathrm{~Tb}^{3+}, \mathrm{ZnB}_{2} \mathrm{O}_{4}: 0.03 \mathrm{~Tb}^{3+}$, $\mathrm{ZnB}_{2} \mathrm{O}_{4}: 0.05 \mathrm{~Tb}^{3+}$ and $\mathrm{ZnB}_{2} \mathrm{O}_{4}: 0.10 \mathrm{~Tb}^{3+}$ samples were reported as $0.189,0.135,0.101,0.140$ and $0.105 \mathrm{~Gy}$, respectively. The kinetic parameters of the $\mathrm{ZnB}_{2} \mathrm{O}_{4}: 0.03 \mathrm{~Tb}^{3+}$ sample were calculated by the glow curve deconvolution, the initial rise, the curve fitting, and the peak shape methods. In conclusion, $\mathrm{ZnB}_{2} \mathrm{O}_{4}: 0.03 \mathrm{~Tb}^{3+}$ phosphor could be a promising material for dosimetric applications.

Funding: This research received no external funding

Conflicts of Interest: The author declares no conflict of interest. 


\section{References}

1. Schubert, D.M.; Alam, F.; Mandana, Z.V.; Knobler, C. Structural characterization and chemistry of the industrially important zinc borate, $\mathrm{Zn}\left[\mathrm{B}_{3} \mathrm{O}_{4}(\mathrm{OH})_{3}\right]$. Am. Chem. Soc. 2003, 15, 866-871.

2. Kaynar, U.H.; Guvener, E.; Ayvacikli, M.; Dogan, T.; Balci-Yegen, S.; Oglakci, M.; Topaksu, M.; Karabulut, Y.; Canimoglu, A.; Benourdja, S.; et al. Anomalous heating rate response of beta irradiated rare earth doped $\mathrm{BaAl}_{2} \mathrm{O}_{4}$ phosphors. J. Alloy. Compd. 2018, 764, 523-529. [CrossRef]

3. Dogan, T.; Tormo, L.; Akca, S.; Kucuk, N.; Guinea, J.G.; Karabulut, Y.; Ayvacikli, M.; Oglakci, M.; Topaksu, M.; Can, N. Low temperature chemical synthesis of $\mathrm{ZnB}_{2} \mathrm{O}_{4}: \mathrm{Eu}^{3+}$ phosphors: Structure, cathodoluminescence and thermoluminescence investigations. Ceram. Int. 2018, 45, 4918-4925. [CrossRef]

4. Zheng, Y.H.; Qu, Y.N.; Tian, Y.M.; Rong, C.G.; Wang, Z.C.; Li, S.L.; Chen, X.; Ma, Y.J. Effect of Eu ${ }^{3+}$-doped on the luminescence properties of zinc borate nanoparticles. Colloids Surf. A: Phys. Eng. Asp. 2009, 349, 19-22. [CrossRef]

5. Kucuk, N.; Ayvacikli, M.; Akca, S.; Yuksel, M.; Guinea, J.G.; Karabulut, Y.; Canimoglu, A.; Topaksu, M.; Can, N. Luminescence studies of zinc borates activated with different concentrations of Ce and La under X-ray and electron excitation. Appl. Radiat. Isot. 2017, 127, 35-40. [CrossRef]

6. $\mathrm{Mu}, \mathrm{Z}$.; $\mathrm{Hu}, \mathrm{Y}$; Chen, L.; Wang, X. Enhanced red emission in $\mathrm{ZnB}_{2} \mathrm{O}_{4}$ : $\mathrm{Eu}^{3+}$ by charge compensation. Opt. Mater. 2011, 34, 89-94. [CrossRef]

7. Li, J.; Zhang, C.X.; Tang, Q.; Zhang, Y.L.; Hao, J.Q.; Su, Q.; Wang, S.B. Synthesis, photoluminescence, thermoluminescence and dosimetry properties of novel phosphor $\mathrm{Zn}\left(\mathrm{BO}_{2}\right)_{2}: \mathrm{Tb}^{3+}$. J. Phys. Chem. Solids 2007, 68, 143-147. [CrossRef]

8. Juan, L.; Chunxiang, Z.; Qiang, T.; Jingquan, H.; Yanli, Z.; Qiang, S.; Shubin, W. Photoluminescence and thermoluminescence properties of dysprosium doped zinc metaborate phosphors. J. Rare Earths 2008, 26, 203-206.

9. Liu, W.R.; Lin, C.C.; Chiu, Y.C.; Yeh, Y.T.; Jang, S.M.; Liu, R.S. $\mathrm{ZnB}_{2} \mathrm{O}_{4}$ : $\mathrm{Bi}^{3+}$, $\mathrm{Eu}^{3+}$ : A highly efficient, red-emitting phosphor. Opt. Express 2010, 18, 2946-2951. [CrossRef]

10. Kucuk, N.; Bulcar, K.; Dogan, T.; Garcia-Guinea, J.; Portaka, Z.G.; Karabulut, Y.; Karabulut, Y.; Ayvacikli, M.; Canimoglu, A.; Topaksu, M.; et al. Doping $\mathrm{Sm}^{3+}$ into $\mathrm{ZnB}_{2} \mathrm{O}_{4}$ phophors and their structural and cathodoluminescence properties. J. Alloy. Compd. 2018, 748, 245-251. [CrossRef]

11. Akca, S.; Oglakci, M.; Portakal, Z.G.; Kucuk, N.; Bakr, M.; Topaksu, M.; Can, N. Thermoluminescence analysis of beta irradiated $\mathrm{ZnB}_{2} \mathrm{O}_{4}: \mathrm{Pr}^{3+}$ phosphors synthesized by a wet chemical method. Radiat. Phys. Chem. 2019, 160, 105-111. [CrossRef]

12. Chen, H.; Wang, Y. Photoluminescence and cathodoluminescence properties of novel rare-earth free narrow band bright green-emitting $\mathrm{ZnB}_{2} \mathrm{O}_{4}: \mathrm{Mn}^{2+}$ phosphor for LEDs and FEDs. Chem. Eng. J. 2019, 361, 314-321. [CrossRef]

13. Rosario, G.C.D.; Cruz-Zaragoza, E.; Hipólito, M.G.; Marcazzó, J.; Hernández, A.J.M.; Murrieta, S.H. Synthesis and stimulated luminescence property of $\mathrm{Zn}\left(\mathrm{BO}_{2}\right)_{2}: \mathrm{Tb}^{3+}$. Appl. Radiat. Isot. 2017, 127, 103-108. [CrossRef] [PubMed]

14. Kucuk, N.; Kucuk, I.; Cakir, M.; Keles, S.K. Synthesis, thermoluminescence and dosimetric properties of La-doped zinc borates. J. Lumin. 2013, 139, 84-90. [CrossRef]

15. Kucuk, N.; Kucuk, I.; Yuksel, M.; Topaksu, M. Thermoluminescence characteristics of $\mathrm{Zn}\left(\mathrm{BO}_{2}\right)_{2}: \mathrm{Ce}^{3+}$ under beta irradiation. Radiat. Prot. Dosim. 2016, 168, 450-458. [CrossRef]

16. Bulcar, K.; Kucuk, N.; Topaksu, M.; Can, N. Thermoluminescence spectra of Tm doped $\mathrm{ZnB}_{2} \mathrm{O}_{4}$ phosphor prepared via a wet-chemical synthesis. Appl. Radiat. Isot. 2019, 147, 177-181. [CrossRef]

17. Shannon, R.D. Revised effective ionic radii and systematic studies of interatomic distances in halides and chalcogenides. Acta Crystallogr. Sect. A 1976, A32, 751-767. [CrossRef]

18. Gieszczyk, W.; Marczewska, B.; Kłosowski, M.; Mrozik, A.; Bilski, P.; Sas-Bieniarz, A.; Goj, P.; Stoch, P. Thermoluminescence Enhancement of $\mathrm{LiMgPO}_{4}$ Crystal Host by $\mathrm{Tb}^{3+}$ and $\mathrm{Tm}^{3+}$ Trivalent Rare-Earth Ions Co-doping. Materials 2019, 12, 2861. [CrossRef]

19. Qu, X.; Cao, L.; Liu, W.; Su, G.; Wang, P.; Schultz, I. Sol-gel synthesis of long-lasting phosphors $\mathrm{CdSiO}_{3}$ : $\mathrm{Mn}^{2+}, \mathrm{RE}^{3+}(\mathrm{RE}=\mathrm{Tb}, \mathrm{Eu}, \mathrm{Nd})$ and luminescence mechanism. Mater. Res. Bull. 2012, 47, 1598-1603. [CrossRef]

20. Muresan, L.E.; Ayvacikli, M.; Guinea, J.G.; Canimoglu, A.; Karabulut, Y.; Can, N. Preparation and characterization of Yttrium based luminescence Phosphors. Opt. Mater. 2017, 74, 150-158. [CrossRef] 
21. Pagonis, V.; Chen, R.; Lawless, J.L. Superlinear dose response of thermoluminescence (TL) and optically stimulated luminescence (OSL) signals in luminescence materials: An analytical approach. J. Lumin. 2012, 132, 1446-1455. [CrossRef]

22. Furetta, C.; Prokic, M.; Salamona, R.; Kitis, G. Dosimetric characterisation of a new production of $\mathrm{MgB}_{4} \mathrm{O}_{7}$ : Dy,Na thermoluminescent material. Appl. Radiat. Isot. 2000, 52, 243-250. [CrossRef]

23. Furetta, C. Handbook of Thermoluminescence; World Scientific Publishing Co. Pte. Ltd.: Singapore, 2010; p. 229.

24. Kucuk, N.; Gozel, A.H.; Yüksel, M.; Dogan, T.; Topaksu, M. Thermoluminescence kinetic parameters of different amount La-doped $\mathrm{ZnB}_{2} \mathrm{O}_{4}$. Appl. Radiat. Isot. 2015, 104, 186-191. [CrossRef] [PubMed]

25. Isik, M.; Yildirim, T.; Gasanly, N.M. Determination of trapping parameters of thermoluminescent glow peaks of semiconducting $\mathrm{Tl}_{2} \mathrm{Ga}_{2} \mathrm{~S}_{3}$ Se crystals. J. Phys. Chem. Solids 2015, 82, 56-59. [CrossRef]

26. Isik, M.; Goksen, K.; Gasanly, N.M.; Ozkan, H. Trap distribution in TlInS 2 layered crystals from thermally stimulated current measurements. J. Korean Phys. Soc. 2008, 52, 367-373. [CrossRef]

27. Annalakshmi, O.; Jose, M.T.; Sridevi, J.; Venkatraman, B.; Amarendra, G.; Mandal, A.B. Kinetic parameters and TL mechanism in cadmium tetra borate phosphor. J. Lumin. 2014, 147, 284-289. [CrossRef]

(C) 2019 by the author. Licensee MDPI, Basel, Switzerland. This article is an open access article distributed under the terms and conditions of the Creative Commons Attribution (CC BY) license (http://creativecommons.org/licenses/by/4.0/). 